\title{
Assessment of Fracture Risk through Radiofrequency Echographic Multi Spectrometry (REMS) based Bone Mineral Density
}

\author{
Elena Kirilova ${ }^{1 *}$, Nikola Kirilov $^{2}$ and Iliya Popov ${ }^{1}$ \\ ${ }^{1}$ University “Prof. Dr. Assen Zlatarov", Burgas, Bulgaria \\ ${ }^{2}$ Medical University of Sofia, Sofia, Bulgaria
}

Submission: September 25, 2019; Published: October 22, 2019

*Corresponding author: Elena Kirilova, University "Prof. Dr. Assen Zlatarov", Burgas, Bulgaria

Abstract

Introduction: Fracture Risk Assessment Tool (FRAX) was developed by the World Health Organization (WHO) to be applicable to both postmenopausal women and men aged 40 to 90 years. The current National Osteoporosis Foundation Guide recommends treating patients with FRAX 10-year risk scores of $>$ or $=3 \%$ for hip fracture or $>$ or $=20 \%$ for major osteoporotic fracture, to reduce their fracture risk.

Methods: 189 postmenopausal women with mean age 60 years \pm 9 standard deviations (SD), (range 40-86) were included in the study. Women were divided in 2 fracture risk groups: 1st - with FRAX score for major osteoporotic fracture below $20 \%$ and for hip fracture below $3 \%$, and 2nd - with FRAX score for major osteoporotic fracture $\geq 20 \%$ and for hip fractures $\geq 3 \%$. Descriptive statistical analysis was used to describe the patients' characteristics in both groups. Independent sample t-test was used to assess the significant association between the quantitative variables and chi-square test - for the qualitative variables.

Results: $77.8 \%$ of the women (147/189) had FRAX score for major osteoporotic fracture below $20 \%$ and $22.2 \%(42 / 189)$ with FRAX score $\geq 20 \% .62 .4 \%$ (118/189) of the women had FRAX score for hip fracture below $3 \%$ and $37.6 \%(71 / 189)$ had FRAX score $\geq 3 \%$. Women with FRAX score for major osteoporotic fracture $\geq 20 \%$ and FRAX score for hip fracture $\geq 3 \%$ were significantly older $(\mathrm{p}=0.000$ ), had significantly lower weight $(\mathrm{p}=0.000)$, height $(\mathrm{p}=0.000)$ and femoral neck BMD $(\mathrm{p}=0.000)$ compared to those with FRAX score for major osteoporotic fracture below $20 \%$ and FRAX score for hip fracture below $3 \%$.

Conclusion: Postmenopausal women at older ages, with low femoral neck BMD, low weight and height, who had previous fractures, have diagnosis of Rheumatoid arthritis (RA) and use corticosteroids are at the highest risk of FRAX for major osteoporotic fractures $\geq 20 \%$ and for hip fractures $\geq 3 \%$.

\section{Introduction}

Osteoporosis is a metabolic bone disease, which is characterized by low bone mass and micro-architectural deterioration of the bone tissue, leading to increased fracture risk. But bone mass alone does not explain the risk of fractures in all osteoporosis cases [1]. The existence of patients with osteoporosis and no fractures and those with osteopenia and multiple fractures proves that bone mineral density (BMD) alone is not enough sensitive for predicting fracture risk. Other independent of BMD risk factors should also be added to provide better fracture risk prediction [2]. Greater understanding of these risk factors could be helpful for prevention of the fractures.

Several fracture risk assessment tools have been implemented $[3,4]$. The most popular tools that are online available are Fracture Risk Assessment Tool (FRAX), Qfracture, FORE 10-Year Fracture Risk Calculator ${ }^{\mathrm{TM}}$ (FORE FRC), Canadian Association of Radiologists and Osteoporosis Canada Risk Assessment Tool (CAROC), Garvan fracture risk calculator and Fracture Absolute
Risk Assessment (FARA) [5-9]. A novel tool - high resolution peripheral quantitative computer tomography (HR-pQCT) was also introduced to predict fractures using reconstructed threedimensional images [10].

FRAX algorithm is a web-based tool (www.shef.ac.uk/FRAX), launched by the University of Sheffield in 2008 and designed to calculate the 10-year probability of major osteoporotic fracture and hip fractures based on obtained clinical risk factors and bone mineral density (BMD). Fracture risk prediction tools are designed to improve the decision about the treatment of people at high absolute risk of fractures. According to the National Osteoporosis Foundation (NOF) treatment is recommended for those patients with BMD of lumbar spine, femoral neck and total hip in the osteoporotic range. For osteopenic subjects (with T-score between -1.0 and -2.5 , osteopenia), a fixed intervention threshold is recommended for all ages and for both sexes set at $20 \%$ for a major osteoporotic fracture and $3 \%$ for hip fracture 
probability [11]. For patients with osteoporosis and increased fracture risk preventive measures such as designing individual therapeutic programs should be adopted [12].

Currently, a new method called Radiofrequency Echographic Multi Spectrometry (REMS) is developed for osteoporosis diagnosis on axial sites at the Italian Institute of Clinical Physiology of the National Council of Research in Lecce (Echolight project) [13]. It is an innovative non-ionizing sonographic approach, which calculate the same diagnostic parameters provided by a Dual-energy X-ray absorptiometry (DXA) examination (BMD, T-score, Z-score, FRAX). The principle of the method is based on acquired radiofrequency signals during an echographic scan of the lumbar spine or femoral neck. The analysis of these native raw unfiltered ultrasound signals allows to keep maximum information about the investigated tissues, which are filtered out after the B-mode image reconstruction. Consideration about the bone status is given after that acquired signal spectra have been compared with previously derived spectral models for pathological and normal conditions. Collected data provides information about bone quantity and quality, so REMS approach is suitable for the estimation of bone strength and for the prediction of fracture risk [14]. A previous published study showed a high degree of correlation between the T-score values provided by the two techniques - REMS and DXA for both lumbar spine $(r=0.94, p<0.001)$ and femoral neck $(r=0.93, p<0.001)$, [12]. Furthermore, REMS technology may have some advantages over DXA method - it is non-ionizing approach and it is portable, so this make it possible to do wider screening of osteoporosis and to detect earlier the cases requiring DXA scanning [15-19].

REMS technology is a non-ionizing axial approach for osteoporosis diagnosis. The operating principle is based on the analysis of native raw unfiltered ultrasound signals, the socalled radiofrequency (RF) ultrasound signals, acquired during an echographic scan of lumbar vertebrae and/or femoral neck. The analysis of native unfiltered ultrasound signals allows to retain the maximum information about the characteristics of the investigated tissues, which are normally filtered out during the conventional process of B-mode image reconstruction. The bone health status is assessed through the comparison of the analyzed signal spectra with previously derived reference spectral models for the considered pathological and normal conditions. The large amount of collected data related to internal bone structure provides both quantity- and qualityrelated information, being thus theoretically suitable for the estimation of bone strength and the prediction of fracture risk. REMS technology is a non-ionizing axial approach for osteoporosis diagnosis. The operating principle is based on the analysis of native raw unfiltered ultrasound signals, the so called radiofrequency (RF) ultrasound signals, acquired during an echographic scan of lumbar vertebrae and/or femoral neck. The analysis of native unfiltered ultrasound signals allows to retain the maximum information about the characteristics of the investigated tissues, which are normally filtered out during the conventional process of B-mode image reconstruction. The bone health status is assessed through the comparison of the analyzed signal spectra with previously derived reference spectral models for the considered pathological and normal conditions. The large amount of collected data related to internal bone structure provides both quantity- and quality-related information, being thus theoretically suitable for the estimation of bone strength and the prediction of fracture risk. The aim of this study is to assess the characteristics of the patients with FRAX score for major osteoporotic fracture $\geq 20 \%$ and for hip fractures $\geq 3 \%$ through REMS technology.

\section{Methods}

189 postmenopausal women with mean age 60 years \pm 9 standard deviations (SD), (range 40-86) were included in the study. Women were divided in 2 fracture risk groups: 1 st - with FRAX score for major osteoporotic fracture below 20\% and for hip fracture below 3\%, and 2nd - with FRAX score for major osteoporotic fracture $\geq 20 \%$ and for hip fractures $\geq 3 \%$. Descriptive statistical analysis was used to describe the patients' characteristics in both groups. Independent sample $t$ test was used to assess the significant association between the quantitative variables and chi-square test - for qualitative variables. Information about the following risk factors was collected - previous fractures, diagnosis of RA, current smoking, current use of glucocorticoids (GC) and alcohol consumption more than $30 \mathrm{ml}$ per day. Chi-square test was used to assess if there is a significant difference between the risk factors in the both fracture risk groups.

\section{Results}

$77.8 \%$ of the women $(147 / 189)$ had FRAX score for major osteoporotic fracture below $20 \%$ and $22.2 \%$ (42/189) had FRAX score $\geq 20 \%$. 62.4\% (118/189) of the women had FRAX score for hip fracture below $3 \%$ and $37.6 \%(71 / 189)$ had FRAX score $\geq 3 \%$. So the majority of the postmenopausal women had FRAX score for major osteoporotic fracture below 20\% and FRAX score for hip fracture below 3\%. Women with FRAX score for major osteoporotic fracture $\geq 20 \%$ were significantly older - with mean age 72.69 years $(y r) \pm 8.2$ SD compared to those with FRAX score for major osteoporotic fracture below 20\% - with mean age 60.84 yr $\pm 9.7 \mathrm{SD},(\mathrm{p}=0.000)$. Women with FRAX score for hip fracture $\geq 3 \%$ were also significantly older - with mean age 72.37 $\mathrm{yr} \pm 7.6$ than those women with FRAX score $<3 \%$ - with mean age $58.13 \mathrm{yr} \pm 8.3 \mathrm{SD}$. The weight of the women with FRAX score for major osteoporotic fracture $\geq 20 \%$ was significantly lower - mean weight 63.6 kilograms $(\mathrm{kg}) \pm 12.9 \mathrm{SD}$ compared to those with FRAX score for major osteoporotic fracture below 20\% - with mean weight $73.6 \mathrm{~kg} \pm 16.4 \mathrm{SD},(\mathrm{p}=0.000)$. Women with FRAX score for hip fracture $\geq 3 \%$ had also significantly lower mean weight $-63.6 \mathrm{~kg} \pm 12.4 \mathrm{SD}$ than those women with FRAX score $<3 \%-76.0 \mathrm{~kg} \pm 16.4 \mathrm{SD},(\mathrm{p}=0.000)$. The group with FRAX score for major osteoporotic fracture $\geq 20 \%$ had significantly lower mean height -151.8 centimeter $(\mathrm{cm}) \pm 6.6 \mathrm{SD}$ and significantly 
lower mean BMD - $0.567 \mathrm{~g} / \mathrm{cm} 2 \pm 0.199 \mathrm{SD}$ compared to the group with FRAX score for major osteoporotic fracture $<20 \%$ $157.7 \mathrm{~cm} \pm 7.6 \mathrm{SD}$ and BMD $0.723 \mathrm{~g} / \mathrm{cm} 2 \pm 0.141 \mathrm{SD}$, ( $\mathrm{p}=0.000)$. The group with FRAX score for hip fracture $\geq 3 \%$ had significantly lower mean height $-152.5 \mathrm{~cm} \pm 7.1 \mathrm{SD}$ and significantly lower mean BMD $-0.579 \mathrm{~g} / \mathrm{cm} 2 \pm 0.098 \mathrm{SD}$ compared to the women with FRAX score for hip fracture $<3 \%$ - height $158.8 \mathrm{~cm} \pm 7.2 \mathrm{SD}$ and BMD $0.735 \mathrm{~g} / \mathrm{cm} 2 \pm 0.121 \mathrm{SD},(\mathrm{p}=0.000)$, (Table 1).

Table 1: Independent sample $t$ test for comparison of age, weight, height and BMD between the two FRAX risk groups; $B M D_{F N}-$ bone mineral density of the femoral neck.

\begin{tabular}{|c|c|c|c|c|c|c|c|}
\hline \multirow{9}{*}{$\begin{array}{c}\text { FRAX } \\
\text { Major osteoporotic }\end{array}$} & & FRAX score & $\mathbf{N}$ & Mean & Std. Deviation & Std. Error Mean & p-value \\
\hline & \multirow{2}{*}{ Age (years) } & $<20 \%$ & 147 & 60.84 & 9.700 & .800 & \multirow{2}{*}{0.000} \\
\hline & & $\geq 20 \%$ & 42 & 72.69 & 8.188 & 1.263 & \\
\hline & \multirow{2}{*}{ Weight (kg) } & $<20 \%$ & 147 & 73.567 & 16.3859 & 1.3515 & \multirow{2}{*}{0.000} \\
\hline & & $\geq 20 \%$ & 42 & 63.610 & 12.8528 & 2.0073 & \\
\hline & \multirow{2}{*}{ Height $(\mathrm{cm})$} & $<20 \%$ & 147 & 157.715 & 7.6493 & .6309 & \multirow{2}{*}{0.000} \\
\hline & & $\geq 20 \%$ & 42 & 151.805 & 6.5773 & 1.0272 & \\
\hline & \multirow{2}{*}{ BMDFN $\left(\mathrm{g} / \mathrm{cm}^{2}\right)$} & $<20 \%$ & 147 & 0.72343 & 0.1408 & 0.0345 & \multirow{2}{*}{0.000} \\
\hline & & $\geq 20 \%$ & 42 & 0.56734 & 0.1987 & 0.0345 & \\
\hline \multirow{8}{*}{ FRAX hip fracture } & \multirow{2}{*}{ age } & $<3 \%$ & 118 & 58.13 & 8.300 & 0.764 & \multirow{2}{*}{0.000} \\
\hline & & $\geq 3 \%$ & 71 & 72.37 & 7.581 & 0.900 & \\
\hline & \multirow{2}{*}{ weight } & $<3 \%$ & 118 & 76.012 & 16.4217 & 1.5117 & \multirow{2}{*}{0.000} \\
\hline & & $\geq 3 \%$ & 71 & 63.614 & 12.4427 & 1.4872 & \\
\hline & \multirow{2}{*}{ height } & $<3 \%$ & 118 & 158.771 & 7.2388 & 0.6664 & \multirow{2}{*}{0.000} \\
\hline & & $\geq 3 \%$ & 71 & 152.473 & 7.1416 & 0.8536 & \\
\hline & \multirow{2}{*}{$\operatorname{BMDFN}\left(\mathrm{g} / \mathrm{cm}^{2}\right)$} & $<3 \%$ & 118 & 0.73506 & 0.1209 & 0.0115 & \multirow{2}{*}{0.000} \\
\hline & & $\geq 3 \%$ & 71 & 0.57876 & 0.0977 & 0.0116 & \\
\hline
\end{tabular}

In the group with FRAX score for major osteoporotic fracture $\geq 20 \%$, women with previous fractures $(\mathrm{N}=32$ ) were about three times more than those without previous fractures $(\mathrm{N}=10)$ and in the group with FRAX score for major osteoporotic fracture $<20 \%$ the same proportion was observed but in benefit of the women without fractures (111/36 - without fractures/ with fractures). These differences were statistically significant $(p=0.000)$. In the group with FRAX score for hip fractures $\geq 3 \%$, women with previous fractures were also more $(\mathrm{N}=40)$ than those women without fractures $(\mathrm{N}=31)$ and in the group with FRAX score for hip fractures $<3 \%$, women without previous fractures were about three times more than those with previous fractures, $(p=0.000)$. There were no statistically significant differences between the number of the smoker and non-smoker in the groups with FRAX score for major osteoporotic fracture and with FRAX score for hip fractures, $(\mathrm{p}=0.072)$. The group with FRAX score for major osteoporotic fractures $\geq 20 \%$ and for hip fractures $\geq 3 \%$ showed higher proportion of the women with CS use/without CS use compared to the group with FRAX score for major osteoporotic fractures $<20 \%$ and for hip fractures $<3 \%$, $(\mathrm{p}=0.009)$. The proportion of the women with RA/without RA was 0.8 in the FRAX group for major osteoporotic fracture $\geq 20 \%$ and about 0.6 in the FRAX group for hip fracture $\geq 3 \%$ and these proportions were significantly higher than the proportion 0.3 in the FRAX group for major osteoporotic fracture $<20 \%$ and for hip fracture $<3 \%,(p=0.015)$. Alcohol consumption more than $30 \mathrm{ml}$ per day was not statistically significant in the groups with FRAX for major osteoporotic fracture and FRAX for hip fractures, $(\mathrm{p}=0.486)$, (Table 2).

Table 2: Chi-square test for the significance of the risk factors in both FRAX risk groups.

\begin{tabular}{|c|c|c|c|c|c|c|}
\hline \multirow{3}{*}{\multicolumn{2}{|c|}{ FRAX Major osteoporotic }} & \multicolumn{2}{|c|}{ FRAX Major osteoporotic } & \multicolumn{2}{|c|}{ FRAX hip fracture } & \multirow{3}{*}{ p-value } \\
\hline & & \multirow{2}{*}{$\begin{array}{l}<20 \% \\
\text { Count }\end{array}$} & \multirow{2}{*}{$\begin{array}{l}\geq 20 \% \\
\text { Count }\end{array}$} & \multirow{2}{*}{$\begin{array}{l}<3 \% \\
\text { Count }\end{array}$} & \multirow{2}{*}{$\begin{array}{c}\geq 3 \% \\
\text { Count }\end{array}$} & \\
\hline & & & & & & \\
\hline \multirow{2}{*}{ Previous fracture } & yes & 36 & 32 & 28 & 40 & 0.000 \\
\hline & no & 111 & 10 & 90 & 31 & \\
\hline \multirow{2}{*}{ smoking } & yes & 38 & 5 & 32 & 11 & 0.072 \\
\hline & no & 109 & 37 & 86 & 60 & \\
\hline \multirow{2}{*}{ Corticosteroid use } & yes & 17 & 14 & 13 & 18 & 0.009 \\
\hline & no & 130 & 28 & 105 & 53 & \\
\hline
\end{tabular}




\section{Orthopedics and Rheumatology Open Access Journal (OROAJ)}

\begin{tabular}{|c|c|c|c|c|c|c|}
\hline \multirow{2}{*}{$\begin{array}{c}\text { Rheumatoid } \\
\text { arthritis }\end{array}$} & yes & 34 & 19 & 26 & 27 & 0.015 \\
\cline { 2 - 7 } & no & 113 & 23 & 92 & 44 & 0.486 \\
\hline $\begin{array}{c}\text { Alcohol } \\
\text { consumption } \\
\text { more than } 30 \mathrm{ml}\end{array}$ & yes & 12 & 2 & 10 & 67 & \\
\cline { 2 - 7 }
\end{tabular}

\section{Discussion}

Osteoporosis is a highly prevalent metabolic bone disease, which leads to bone fragility and subsequent fractures, most of them with social and economic impact. The necessity of adequate treatment for individuals at high risk of fractures brought about the need for new risk prediction models. FRAX algorithm, released in 2008 by WHO, is a fracture risk assessment tool, which gives 10-year probability for major osteoporotic fractures and hip fractures $[20,21]$. The clinical risk factors in the FRAX model are on one hand easily accessible and on the other hand highly validated from an evidence-based assessment [22]. Furthermore, FRAX tool has been incorporated into the software of some DXA scanners $[23,24]$. In the current study, the opportunity to assess the 10-year fracture risk with REMS technology, which has integrated Fracture Risk Assessment Tool (FRAX) [25], motivated us to describe the patients' characteristics in the different FRAX risk groups with this novel method.

We found out that the incidence of FRAX for major osteoporotic fractures was $22.2 \%$ and the incidence of FRAX for hip fractures $\geq 3 \%$ was $37.6 \%$. FRAX score was calculated using the following risk factors - age, weight, height, BMD, previous fractures, current smoking, diagnosis of RA, current use of corticosteroids and alcohol consumption more than $30 \mathrm{ml}$ per day. We observed statistically significant differences for age, weight, height, BMD, current use of corticosteroids, previous fractures and diagnosis of RA between the groups with FRAX for major osteoporotic $\geq 20 \%$ and with FARX for major osteoporotic $<20 \%$. The same results were observed in the groups with FRAX score for hip fracture $\geq 3 \%$ and with FRAX score for hip fracture $<3 \%$.

Results in the current study showed that age is a very important risk factor for FRAX major osteoporotic and for hip fractures due to statistically significant differences in the age between the women in the both FRAX groups. The influence of the FRAX risk assessment by the age is in accordance with the data provided by the National Osteoporosis Group [11]. In the study of Gadam et al. age was the only risk factor in postmenopausal women that was significantly different between those with identical and different predictions [26-29]. The indicators - weight and height are significant risk factors for FRAX major osteoporotic $\geq 20 \%$ and for hip fractures $\geq 3 \%$ in our study. Similar results are observed in the other FRAX studies. Body mass index (BMI), an indicator compounded of weight and height, showed negative association with FRAX-based fracture probabilities in the previous studies. This association was especially significant in subjects with a BMI less than $19 \mathrm{~kg} / \mathrm{m}^{2}$, while for subjects with a BMI greater than $19 \mathrm{~kg} / \mathrm{m}^{2}$, the fracture risk remained relatively stable [30-32].

According to the World Health Organization (WHO) criteria, BMD measured by dual-energy X-ray absorptiometry (DXA), is the most widely used in the diagnosis of osteoporosis [33]. Although a low BMD is a determinant of osteoporotic fracture, some fracture cases did not have a BMD in the osteoporotic range [34-36]. According to Kanis et al. the prediction of fractures with the use of clinical risk factors alone in FRAX is comparable to the use of BMD alone to predict fractures. In the current study patients with lower BMD showed significantly higher FRAX score for major osteoporotic fractures and for hip fractures, which is in accordance with the previous studies [37-39].

According to our study presence of previous fracture was significant for FRAX major osteoporotic $\geq 20 \%$ and for hip fractures $\geq 3 \%$. It is beyond controversy that previous fractures increase the risk of future fractures [20,37]. In the study of Morin et al. non-traumatic fractures in women were associated with osteoporosis at the femoral neck and the authors showed that the site of previous fractures impacts future fracture risk, independent of the BMD value [40].

RA has been incorporated as a dichotomous predictor in the WHO FRAX algorithm for predicting the 10-year risk of hip or major osteoporotic fracture. In our study RA was significant for FRAX major osteoporotic and FRAX for hip fractures. Several studies showed in alignment with our study that the incidence of fracture is higher in RA patients than in controls [41-44]. FRAX could be underestimated due to the lack of information about the severity of RA and on the contrary it may overestimate fracture risk due to higher mortality among patients with RA [45]. The use of corticosteroids (CS) has been incorporated as one of the clinical risk factors for calculating the 10-year fracture risk in the Fracture Risk Assessment Tool (FRAX). CS can have impact on the fracture risk independent of bone density [46]. According to Kanis et al. the exposure to glucocorticoids was found to be significant for fracture probability. Fracture probabilities increased with $15 \%$ for high doses of CS (> $7.5 \mathrm{mg}$ daily).

\section{Conclusion}

Postmenopausal women at older ages, with low femoral neck BMD, low weight and height, who had previous fractures, have diagnosis of RA and use corticosteroids are at the highest risk of FRAX for major osteoporotic fractures $\geq 20 \%$ and for hip fractures $\geq 3 \%$. 


\section{Orthopedics and Rheumatology Open Access Journal (OROAJ)}

\section{References}

1. Buchbinder R, Johnston RV, Rischin KJ, Homik J, Jones CA, et al. (2018) Percutaneous vertebroplasty for osteoporotic vertebral compression fracture. Percutaneous vertebroplasty for osteoporotic vertebral compression fracture. Cochrane Database Syst Rev 4: CD006349.

2. Silverman SL, Calderon AD (2010) The Utility and Limitations of FRAX: A US Perspective. Curr Osteoporos Rep 8(4): 192-197.

3. Kanis JA, McCloskey EV, Johansson H, Cooper C, Rizzoli R, et al. (2019) European guidance for the diagnosis and management of osteoporosis in postmenopausal women. Osteoporos Int 30(1): 3-44.

4. Kanis JA (2007) on behalf of the World Health Organization Scientific Group . Assessment of osteoporosis at the primary health-care level. Technical Report. World Health Organization Collaborating Centre for Metabolic Bone Diseases, University of Sheffield, UK.

5. Ettinger B, Liu H, Blackwell T, Hoffman AR, Ensrud KE, et al. (2012) Validation of FRC, a fracture risk assessment tool, in a cohort of older men: the Osteoporotic Fractures in Men (MrOS) Study. J Clin Densitom 15(3): 334-342.

6. Hippisley-Cox J, Coupland C (2012) Derivation and validation of updated QFracture algorithm to predict risk of osteoporotic fracture in primary care in the United Kingdom: prospective open cohort study. BMJ 344: e3427.

7. Kanis JA, Harvey NC, Johansson H, Odén A, McCloskey EV, et al. (2017) Overview of Fracture Prediction Tools. J Clin Densitom 20(3): 444-450.

8. Leslie WD, Berger C, Langsetmo L, Lix LM, Adachi JD, et al. (2011) Construction and validation of a simplified fracture risk assessment tool for Canadian women and men: results from the CaMos and Manitoba cohorts. Osteoporos Int 22(6): 1873-1883.

9. Williams ST, Lawrence PT, Miller KL, Crook JL, LaFleur J, et al. (2017) A comparison of electronic and manual fracture risk assessment tools in screening elderly male US veterans at risk for osteoporosis. Osteoporos Int 28(11): 3107-3111.

10. Cheung AM, Adachi JD, Hanley DA, Kendler DL, Davison KS, et al. (2013) High-resolution peripheral quantitative computed tomography for the assessment of bone strength and structure: a review by the Canadian Bone Strength Working Group. Curr Osteoporos Rep 11(2): 136-146.

11. Kanis JA, Harvey NC, Cooper C, Johansson H, Odén A, et al. (2016) A systematic review of intervention thresholds based on FRAX : A report prepared for the National Osteoporosis Guideline Group and the International Osteoporosis Foundation. Arch Osteoporos 11(1): 25.

12. Tomasevic-Todorovic S, Vazic A, Issaka A, Hanna F (2018) Comparative assessment of fracture risk among osteoporosis and osteopenia patients: a cross-sectional study. Open Access Rheumatol 10:61-66.

13. Pisani P, Renna MD, Conversano F, Casciaro E, Muratore M, et al. (2013) Screening and early diagnosis of osteoporosis through X-ray and ultrasound-based techniques. World J Radiol 5(11): 398-410.

14.Diez-Perez A, Brandi ML, Al-Daghri $\mathrm{N}$, Branco JC, Bruyère $\mathrm{O}$, et al. (2019) Radiofrequency echographic multi-spectrometry for the in-vivo assessment of bone strength: state of the art-outcomes of an expert consensus meeting organized by the European Society for Clinical and Economic Aspects of Osteoporosis, Osteoarthritis and Musculoskeletal Diseases (ESCE0). Aging Clin Exp Res 31(10): 1375-1389.

15. Aventaggiato M, Conversano F, Pisani P, Casciaro E, Franchini R, et al. (2016) Validation of an automatic segmentation method to detect vertebral interfaces in ultrasound images. IET Sci Measurement Technol 10: 18-27.

16. Bojincă VC, Popescu CC, Decianu RD, Dobrescu A, Bălănescu SM, et al. (2019) A novel quantitative method for estimating bone mineral density using B-mode ultrasound and radiofrequency signals-a pilot study on patients with rheumatoid arthritis. Exp Ther Med 18(3):1661-1668.

17. Casciaro S, Peccarisi M, Pisani P, Franchini R, Greco A, et al. (2016) An advanced quantitative echosound methodology for femoral neck densitometry. Ultrasound Med Biol 42(6): 1337-1356.

18. Crespo DO, Nogues X, Diez-Perez A (2019) Sat0710-hpr radiofrequency echographic multi spectrometry osteoporosis diagnosis on femoral neck: a spanish clinical experience. Annals of the Rheumatic Diseases 78: 1457 .

19. Di Paola M, Gatti D, Viapiana O, Cianferotti L, Cavalli L, et al. (2019) Radiofrequency echographic multispectrometry compared with dual X-ray absorptiometry for osteoporosis diagnosis on lumbar spine and femoral neck. Osteoporos Int 30(2): 391-402.

20. Kanis JA (2008) On behalf of the World Health Organization Scientific Group. Assessment of osteoporosis at the primary health-care level. Technical report. University of Sheffield, WHO Coolaborating Center, UK.

21. Kanis JA, Johnell O, Oden A, Johansson H, McCloskey E (2008) FRAX and the assessment of fracture probability in men and women from the UK. Osteoporos Int 19(4): 385-397.

22. Kanis JA, McCloskey E, Johansson H, Oden A, Leslie WD (2012) FRAX with and without bone mineral density. Calcif Tissue Int 90(1): 1-13.

23. Cezary Iwaszkiewicz, Piotr Leszczyński (2019) Bone densitometry by radiofrequency echographic multi-spectrometry (REMS) in the diagnosis of osteoporosis. Forum Reumatologiczne 5(2): 81-88.

24. U.S. Food \& Drug Administration (2018) Echolight S.p.a. EchoS 510(K) Premarket Notification.

25. Aubry-Rozier B, Stoll D, Krieg MA, Lamy O, Hans D (2013) What was your fracture risk evaluated by FRAX $₫$ the day before your osteoporotic fracture. Clin Rheumatol 32: 219-223.

26. Bolland MJ, Grey A, Gamble G, Reid IR (2013) Comment on Kanis et al.: Pitfalls in the external validation of FRAX. Osteoporos Int 24(1): 389- 390.

27. Gadam RK, Schlauch K, Izuora KE (2013) Frax prediction without BMD for assessment of osteoporotic fracture risk. Endocr Pract 19(5): 780784.

28. Sornay-Rendu E, Munoz F, Delmas PD, Chapurlat RD (2010) The FRAX tool in French women: How well does it describe the real incidence of fracture in the OFELY cohort? J Bone Miner Res 25: 2101-2107.

29. Armstrong ME, Spencer EA, Cairns BJ, Banks E, Pirie K, et al. (2011) Body mass index and physical activity in relation to the incidence of hip fracture in postmenopausal women. J Bone Miner Res 26(6): 13301338.

30. Gao G, Zhang ZL, Zhang H, Hu WW, Huang QR, et al. (2008) Hip axis length changes in 10,554 males and females and the association with femoral neck fracture. J Clin Densitom 11((3): 360-366.

31. Wang J, Wang X, Fang Z, Lu N, Han L (2017) The Effect of FRAX on the Prediction of Osteoporotic Fractures in Urban Middle-aged and Elderly Healthy Chinese Adults. Clinics (Sao Paulo) 72(5): 289-293.

32. World Health Organisation (1994) WHO Technical Report Series 843. In Assessment of Fracture Risk and its Application to Screening for Postmenopausal Osteoporosis; WHO, Geneva, Switzerland.

33. Nguyen ND, Eisman JA, Center JR, Nguyen TV (2007) Risk factors for fracture in nonosteoporotic men and women. J Clin Endocrinol Metab 92(3): 955-962. Osteoporos Int 24(1): 23-57.

34. Pasco JA, Seeman E, Henry MJ, Merriman EN, Nicholson GC, et al. (2006) The population burden of fractures originates in women with osteopenia, not osteoporosis. Osteoporos Int 17(9): 1404-1409. 
35. Prawiradilaga RS, Gunmalm V, Lund-Jacobsen T, Helge EW, Brøns C, et al. (2018) FRAX Calculated without BMD Resulting in a Higher Fracture Risk Than That Calculated with BMD in Women with Early Breast Cancer. J Osteoporos 2018: 4636028.

36. FRAX: World Health Organization Fracture Risk Assessment Tool, 3.1 ed. World Health Organization, Sheffield, United Kingdom.

37. Briot K, Paternotte S, Kolta S, Eastell R, Felsenberg D, et al. (2013) FRAX@: prediction of major osteoporotic fractures in women from the general population: the OPUS study. PLoS One 8(12): e83436.

38. Marques A, Lucas R, Simões E, Verstappen SMM, Jacobs JWG, et al. (2017) Do we need bone mineral density to estimate osteoporotic fracture risk? A 10-year prospective multicentre validation study. RMD Open 3(2): e000509.

39.Morin SN, Lix LM, Leslie WD (2014) The importance of previous fracture site on osteoporosis diagnosis and incident fractures in women. J Bone Miner Res 29(7): 1675-1680.

40. Kim SY, Schneeweiss S, Liu J, Daniel GW, Chang CL, et al. (2010) Risk of osteoporotic fracture in a large population-based cohort of patients with rheumatoid arthritis. Arthritis Res Ther 12(4): R154.

41. Terpos E, Fragiadaki K, Konsta M, Bratengeier C, Papatheodorou A, et al. (2011) Early effects of IL-6 receptor inhibition on bone homeostasis: a pilot study in women with rheumatoid arthritis. Clin Exp Rheumatol 29(6): 921-925.

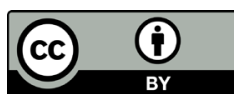

This work is licensed under Creative Commons Attribution 4.0 License DOI: 10.19080/OROAJ.2019.15.555905
42. Van Staa TP, Geusens P, Bijlsma JW, Leufkens HG, Cooper C (2006) Clinical assessment of the long-term risk of fracture in patients with rheumatoid arthritis. Arthritis Rheum 54(10): 3104-3112.

43. Vladeva S (2014) Rheumatology aspects of the general practice. Osteoporosis Zhanina, Stara Zagora, p. 5-15.

44. Klop C, de Vries F, Bijlsma JWJ, Leufkens HG, Welsing PM, et al. (2016) Predicting the 10-year risk of hip and major osteoporotic fracture in rheumatoid arthritis and in the general population: an independent validation and update of UK FRAX without bone mineral density. Ann Rheum Dis 75(12): 2095-2100.

45. Leib ES, Saag KG, Adachi JD, Geusens PP, Binkley N, et al. (2011) FRAX(®) Position Development Conference Members. Official Positions for FRAX clinical regarding glucocorticoids: the impact of the use of glucocorticoids on the estimate by FRAX of the 10-year risk of fracture from Joint Official Positions Development Conference of the International Society for Clinical Densitometry and International Osteoporosis Foundation on FRAX. J Clin Densitom 14(3): 212-219.

46. Kanis JA, Johansson H, Oden A, McCloskey EV (2011) Guidance for the adjustment of FRAX according to the dose of glucocorticoids. Osteoporos Int 22(3): 809-816.

\section{Your next submission with Juniper Publishers will reach you the below assets}

- Quality Editorial service

- Swift Peer Review

- Reprints availability

- E-prints Service

- Manuscript Podcast for convenient understanding

- Global attainment for your research

- Manuscript accessibility in different formats

( Pdf, E-pub, Full Text, Audio)

- Unceasing customer service

Track the below URL for one-step submission https://juniperpublishers.com/online-submission.php 